\title{
SOUND PRODUCTION LEARNING AND THE CONTIGUUM HYPOTHESIS
}

\author{
PEDRO TIAGO MARTINS ${ }^{* 1,2}$ and CEDRIC BOECKX ${ }^{1,2,3}$ \\ ${ }^{*}$ Corresponding Author: pmartima23@alumnes.ub.edu \\ ${ }^{1}$ Section of General Linguistics, University of Barcelona, Barcelona, Spain \\ ${ }^{2}$ University of Barcelona Institute of Complex Systems, Barcelona, Spain \\ ${ }^{3}$ ICREA, Barcelona, Spain
}

\section{Introduction}

Besides humans, vocal learning is also attested in some bird lineages (songbirds, parrots, hummingbirds), some cetaceans, bats, pinnipeds and some elephants (Ravignani et al., 2016). Vocal learning is usually seen as a transparent behavioral trait, with an associated neural substrate, and typically a species is said to either have it or not (i.e. species are said to be "vocal learners" or "vocal non-learners"). This classification guides research on a variety of topics when it comes to understanding the evolution of vocal learning and its relationship with other languagerelated traits. However, there have been attempts at a more nuanced view, resulting in non-dichotomous typologies of vocal learning that include more species and a wider spectrum of capacities. A notable example is the continuum hypothesis put forward by Arriaga and Jarvis (2013), for which they propose a more nuanced scheme of vocal learning, going beyond the traditional all-or-nothing view and incorporating cases of species which do not conform to that reductionist classification, namely those who can produce novel vocalizations without mimicry (see Petkov and Jarvis (2012) for a review of evidence in this direction).

\section{Proposal}

In this work, we continue in the same vein and recontextualize vocal learning as a case of sound production learning, a more general sound production ability that does not necessarily rest on vocal control. We present this as part of a contiguum hypothesis, as a way of emphasizing abilities that border on and interact with others by virtue of sharing common ground at different levels. This will allow us to bring our close relatives into the fold, and foster non-human primate research on aspects (behavioral, ecological, neural, and genetic) that play an important role in language and allow us to peer into its evolution in more permissive ways (see Lameira, 2017 for related discussion and literature). There are several reasons for attempting to do so. 
1. It has been shown in recent years that the vocal tract of many non-human primates is not a obstacle (Fitch, de Boer, Mathur, \& Ghazanfar, 2016) to vocal abilities. If vocal anatomy is abandoned as a proxy for species worth studying, the number of interesting species for the study of language evolution increases tremendously.

2. Another important reason has to do with volition. For example, even though many primates lack the laryngeal control necessary for bona fide vocal learning, some can still modulate calls by external means, such as using their hands or a leaf in front of their mouth. This contributes e.g. to size exaggeration (Lameira, Hardus, \& Wich, 2011). Orangutans also seem to be able to spontaneously acquire and modulate human-like whistles (Wich et al., 2009). Other species, like gibbons, are able to propagate their vocalizations across long distances by reconfiguring their vocal tract in ways akin to soprano singing (Koda et al., 2012). We will present examples showing that some species have ways of going around their lack of laryngeal control by other means and still produce sounds beyond their innate repertoire. We will propose that vocal control is not the only piece of the puzzle of controlled vocalizations.

3. One other, crucial reason has to do with the brain. The brain "signature" of vocal learning species is a direct connection between the motor cortex and the larynx (in birds, the arcopallium and syrinx), which endows them with the necessary vocal control. Opening up the set of interesting abilities to a wider sound production learning capacity invites the exploration of different brain structures and pathways putatively relevant.

\section{Final remarks}

As with many other dichotomies (e.g. innate/learned, nature/nurture), a strict, allor-nothing classification of vocal learning misses important distinctions that rest on finer-grained behavioral and neuroanatomical traits, something which in turn Arriaga and Jarvis (2013) capture with their continuum hypothesis. We extend this way of proceeding beyond specific traits, and generalize it, using a generic notion of vocal abilities as proof of concept.

By examining cognition as a "contiguous" space, where borders may be apparent at any one level, but vanish when others are taken into account, we intend to capture the non-hierarchical, multi-directional character of the evolution of complex traits. Instead of thinking of straight lines from stage $A$ to stage $B$, or trees that bifurcate at node $A$ and yield $A$ and $B$, a more fruitful approach when studying complex traits is to think of a territory, where dividing lines do exist, but traversing them is the rule rather than the exception. We find this particularly useful in the study of language evolution, which clearly defies the "speciality" that known dichotomies (e.g. Faculty of Language in the Narrow Sense (FLN)/Faculty of Language in the Broad Sense (FLB), Hauser et al. 2002) so vehemently embody, with little progress. 


\section{References}

Arriaga, G., \& Jarvis, E. D. (2013). Mouse vocal communication system: Are ultrasounds learned or innate? Brain and language, 124(1). doi: 10.1016/ j.bandl.2012.10.002

Fitch, W. T., de Boer, B., Mathur, N., \& Ghazanfar, A. A. (2016). Monkey vocal tracts are speech-ready. Science Advances, 2(12), e1600723. doi: 10.1126/sciadv.1600723

Hauser, M. D., Chomsky, N., \& Fitch, W. T. (2002). The Faculty of Language: What Is It, Who Has It, and How Did It Evolve? Science, 298, 1569-1579.

Koda, H., Nishimura, T., Tokuda, I. T., Oyakawa, C., Nihonmatsu, T., \& Masataka, N. (2012). Soprano singing in gibbons. American Journal of Physical Anthropology, 149(3), 347-355. doi: 10.1002/ajpa.22124

Lameira, A. R. (2017). Bidding evidence for primate vocal learning and the cultural substrates for speech evolution. Neuroscience \& Biobehavioral Reviews, 83(Supplement C), 429-439. doi: 10.1016/j.neubiorev.2017.09.021

Lameira, A. R., Hardus, M. E., \& Wich, S. A. (2011). Orangutan Instrumental Gesture-Calls: Reconciling Acoustic and Gestural Speech Evolution Models. Evolutionary Biology, 39(3), 415-418. doi: 10.1007/ s11692-011-9151-6

Petkov, C. I., \& Jarvis, E. (2012). Birds, primates, and spoken language origins: Behavioral phenotypes and neurobiological substrates. Frontiers in Evolutionary Neuroscience, 4. doi: 10.3389/fnevo.2012.00012

Ravignani, A., Fitch, W. T., Hanke, F. D., Heinrich, T., Hurgitsch, B., Kotz, S. A., ... de Boer, B. (2016). What Pinnipeds Have to Say about Human Speech, Music, and the Evolution of Rhythm. Frontiers in Neuroscience, 10. doi: 10.3389/fnins.2016.00274

Wich, S. A., Swartz, K. B., Hardus, M. E., Lameira, A. R., Stromberg, E., \& Shumaker, R. W. (2009). A case of spontaneous acquisition of a human sound by an orangutan. Primates, 50(1), 56-64. doi: 10.1007/s10329-008 $-0117-\mathrm{y}$ 